\title{
Analisis Perbandingan Komitmen Bidan Koordinator dalam Pencatatan dan Pelaporan PWS KIA di Kabupaten Kapuas
}

\author{
Kristie Hapsari*, Sutopo Patria Jati**, Mateus Sakundru Adi** \\ *Dinas Kesehatan Kabupaten Kapuas \\ ** Fakultas Kesehatan Masyarakat, Universitas Diponegoro \\ Email chrisaiye@gmail.com
}

\begin{abstract}
The midwife's commitment in recording the PWS KIA (Pemantauan Wilayah Setempat Kesehatan Ibu dan Anak / Maternal and Child Health Area Monitoring) is a form of responsibility in reporting the PWS KIA and contributing to the achievement of the PWS KIA target. The lack of data and information on PWS KIA can lead to achievement of low and not low targets and cause PWS KIA problems to be resolved. Observation results of the PWS KIA Kapuas report found problems, namely; the report is incomplete, only partially filled in, even the number of formats sent is different for each Public Health Center. This research is a qualitative research. Data collected using questionnaires and in-depth interviews. The object of this study was the coordinating midwife and the Head of the Basic Health Services Section as the person in charge of PWS KIA in Kapuas Regency. The results showed that midwife coordinator with high commitment supported, among others; long work experience, has the attitude and responsibility for the trust that was stabbed, SK was appointed as a coordinating midwife, had a SOP supporting document PWS KIA report, received support from head of $P H C$ and coworkers as well as the monitoring and
\end{abstract}

evaluation from the Kapuas District Health Office where the condition was not obtained from coordinating midwives with "low commitment". It is recommended to increase support for all coordinating midwives in the recording and reporting of PWS KIA in the form of supervision of the Kapuas District Health Office with quality activities, both the time and the material delivered.

Keywords: $\quad$ Commitment, $\quad$ Midwife Coordinator, PWS KIA

\section{PENDAHULUAN}

Komitmen Bidan dalam pencatatan PWS KIA (Pemantauan Wilayah Setempat Kesehatan Ibu dan Anak) merupakan bentuk tanggung jawab dalam pencatatan pelaporan PWS KIA dan memberikan kontribusi pencapaian target KIA. ${ }^{1}$ Kurangnya data dan informasi yang cepat dan akurat dapat menyebabkan pencapan target program - program yang dibuat oleh Dinas Kesehatan menjadi tidak akurat dan mengakibatkan permasalahan KIA di masyarakat tidak teratasi.

Data - data pencapaian target tersebut dapat diketahui dengan melakukan pencatatan dan pelaporan PWS KIA yang dilakukan oleh seluruh Bidan Pelaksana program KIA di wilayah kerjanya sebagai salah satu tugas pokok sesuai dengan Permenkes RI Nomor: 
1464/ Menkes/ PER/ 2010. ${ }^{2}$ Komitmen Bidan dalam pencatatan PWS KIA merupakan bentuk tanggung jawab dalam pencatatan pelaporan PWS KIA dan memberikan kontribusi pencapaian target KIA. $^{3}$

Kabupaten Kapuas memberikan kontribusi yang besar terhadap AKI/AKB bahkan berada pada posisi kedua seprovinsi Kalimantan Tengah, pada tahun 2017 tercatat data AKI berjumlah 9 kasus dan AKB sebanyak 45 kasus. Berdasarkan data laporan PWS KIA Dinas Kesehatan Kabupaten Kapuas pada tahun 2018 ada 11 puskesmas yang pencapaian kunjungan bumil pertama (K1) dibawah target nasional yaitu $100 \%$ bahkan ada 3 puskesmas yang pencapaiannya dibawah $50 \%$. Pencapaian kunjungan kehamilan semester tiga (K4) di Kabupaten Kapuas hanya $79 \%$ sedangkan target yang telah ditentukan 95\%. Demikian pula dengan pencapaian pertolongan Persalinan oleh Nakes (PN) masih terdapat 5 Puskesmas dengan pencapaian PN kurang dari target nasional $90 \%$.

Hasil pengamatan pada laporanlaporan yang dikirim oleh bidan koordinator ke Dinas Kesehatan Kabupaten Kapuas pada tahun 2018, ditemukan beberapa masalah, antara lain; laporan tidak lengkap, hanya diisi sebagian saja bahkan jumlah format yang dikirimkan berbeda tiap - tiap puskesmas. Dari 26 puskesmas hanya ada 5 puskesmas yang mengirimkan format dengan lengkap, ada sebanyak 5 puskesmas yang tidak menyerahkan laporan hingga 3 bulan.

Oleh karena itu perlu adanya analisis perbandingan lebih lanjut tentang komitmen bidan koordintor dalam pencatatan dan pelaporan PWS KIA. Tujuan penelitian ini adalah untuk mengetahui bagaimana perbandingan komitmen bidan koordintor dalam pencatatan dan pelaporan PWS KIA di Dinas Kesehatan Kabupaten Kapuas

\section{METODE PENELITIAN}

Penelitian ini adalah penelitian kualitatif. Metode pengumpulan data menggunakan kuesioner yang disebarkan kepada seluruh bidan koordinator sebanyak 26 orang untuk mengetahui kategori bidan dengan komitmen tinggi dan komitmen rendah. telaah laporan PWS KIA, melakukan observasi ruang KIA di puskesmas untuk melihat kelengkapan dokumen laporan PWS KIA dan dilanjutkan wawancara mendalam dengan penekanan pada pertanyaan variabel yang dapat mewakili tentang komitmen, antara lain: Pengalaman Kerja, Sikap Bidan, Dokumen PWS KIA, Dukungan Kepala Puskesmas, Dukungan Rekan Kerja dan Suvervisi dari Dinas Kesehatan.

Objek penelitian ini adalah bidan koordinator sebanyak 6 orang yaitu, 3 orang bidan yang memiliki "komitmen tinggi" dan 3 orang bidan dengan "komitmen rendah'. sebagai informan triangulasi adalah Kepala Puskesmas dan Kepala Seksi Yankesdas selaku penanggung jawab KIA Kabupaten Kapuas..

\section{HASIL DAN PEMBAHASAN}

Dari hasil penghitungan skor kuesioner yang disebarkan kepada seluruh bidan koordinator tentang pencatatan dan pelaporan PWS KIA di wilayah kerja Dinas Kesehatan Kabupaten Kapuas maka akan di buat pengelompokan skor menurut kategori; "komitmen tinggi" dan "komitmen rendah".

Terdapat $65 \%$ bidan koordinator yang memiliki komitmen tinggi dalam pencatatan dan pelaporan PWS KIA, sedangkan 35\% lainnya termasuk kategori komitmen rendah. Dari hasil penilaian komitmen maka dipilih 6 orang sebagai informan utama yaitu bidan koordinator 
dengan komitmen 3 orang yang mewakili bidan koordinator dengan: komitmen tinggi dan 3 orang mewakili "komitmen rendah" sebagai pertimangan penilaian juga berdasarkan hasil telaah dokumen laporan PWS KIA kabupaten.

Rerata responden sudah bekerja selama 4 sampai dengan 15 tahun. Seluruh responden berstatus sebagai PNS dan memiliki latar belakang pendidikan D3.

\section{Komitnen Bidan Koordinator Dari Aspek Pengalaman Kerja}

Pada hasil wawancara tentang pengalaman kerja ditemukan ada perbedaan informasi antara bidan koordinator yang memiliki "komitmen tinggi" dengan bidan koordinator yang memiliki "komitmen rendah".

...biasa saja, tidak ada kendala, bikin laporan KIA kan sejak pertama tugas dulu cuman sekarang banyak sekali isinya, KIA 14 lembar, bagi-bagi tugas (UI4)

...karena sudah biasa aja kak.. karena memang menulis, merekap apa yang kita kerjakan setiap bulan, jadi laporan bisa cepat selesai (IU5)

...agaknya kadang-kadang kada ngerti DOnya, jadi sering sering salah isi angka-angka di laporan jadi harus baca dan tanya ke lain (IU1)

...belum lama jadi bikor, sebenarnya waktu di polindes aja masih agak kurang paham laporan KIA, paling takut bila salah menghitung (IU3)

Hal ini diperkuat lagi dengan pernyataan informan triangulasi. ...sepertinya biasa saja, sudah pada tau kalau bidan laporannya ya PWS KIA, paling ngeluh jumlah format. (IT2)

...laporan PWS KIA kan sudah lama, sudah biasa dikerjan oleh bidan, sejak terjun ke lapangan termasuk yang kerja di desa, saya kira mereka sudah biasa mengerjakannya. (IT1)

Memahami dan menbaca dengan teliti format laporan PWS KIA yang sudah didesain sedemikian baik perlu ditingkatkan oleh bidan koordinator itu sendiri sehingga baik yang memiliki pengalaman lama ataupun tidak dapat memahami definisi operasional dan format laporan yang ada terlebih PWS KIA sudah ada sejak lama. Laporan PWS KIA memang memiliki jumlah format banyak namun data pada format tersebut sangat penting untuk proram KIA sehingga bila dalam pengelolaannyan dapat disiasati dengan membagi tugasnya kepada sesama bidan yang ada di ruang KIA, cara ini akan sangat membantu meringankan beban bidan koordinator.

Pada pengalaman kerja ini juga ditanyakan bagaimana proses pencatatan dan pelaporan PWS KIA, disini ditemui bahwa bidan koordinator dengan "komitmen tinggi" lebih sistematis dalam pekerjaannya dimana bidan-bidan ini dapat merinci proses sampai dengan melakukan evaluasi terhadap pencapaian target KIA. Bidan dengan masa kerja lebih dari lima tahun memiliki komitmen yang cukup baik dalam pencatatan dan pelaporan PWS KIA, seorang bidan koordinator dapat dikatakan memiliki pengalaman kerja jika sudah melakukan pekerjaan secara berulang-ulang dalam waktu atau masa kerja yang cukup lama serta dapat memahami tugas-tugas suatu pekerjaan dan telah melaksanakan dengan 
baik. Hal ini sesuai dengan penelitian sebelumnya pada tahun 2015 di Puskesmas Duren yang menyatakan bahwa terdapat keterkaitan antara masa kerja terhadap kualitas data pada pencatatan PWS KIA. ${ }^{4}$

Keadaan ini sesuai dengan pernyataan Meyer, Allen \& Smith bahwa karyawan yang telah bekerja cukup lama dalam organisasi yang selalu konsisten dalam ekspektasi yang diharapkan serta pemuasan kebutuhan dasarnya akan cenderung untuk membentuk ikatan afektif yang lebih kuat terhadap organisasi daripada karyawan yang memiliki pengalaman lebih sedikit. ${ }^{5}$

\section{Komitnen Bidan Koordinator Dari Aspek Sikap}

Sikap kerja adalah keinginan untuk mencapai hasil yang diharapkan, sikap ini dapat timbul dari dalam diri sendiri ataupun lingkungan tempat kerja. Sikap ini erat hubungannya dengan bagaimana seorang bidan koordinator berpendapat tentang pekerjaannya, bersedia untuk tetap memiliki posisi sebagai bidan koordinator.

..kalau bisa ganti, saya memilih kada jadi bidan koordinator lagi (IU1)

...terpaksa saja jadi bidan koordinator, karena tidak ada orang yang mau (IU2)

...terpaksa aja nah...kalau bisa ganti (IU3)

...kalau masih dipercaya, saya siap (IU4)

...selama diberi tanggung jawab sebagai bikor,saya kerja terus (IU5).

Bidan koordinator terlihat bila yang mempunyai "komitmen rendah" cendrung merasa jabatan bidan koordinator yang diterimanya adalah sebuah keterpaksaan dan ingin diganti. Sedangkan yang memiliki "komitmen tinggi" lebih siap bekerja sebagai bidan koordinator karena sudah diberi tanggung jawab oleh puskesmas.

....memang susah mencari yang mau jadi bidan koordinator, jadi ada yang terpaksa juga, yang penting ada bidan koordinator di puskesmas (IT 2)

...saya tetap pertahankan yang sudah ada sebagai bikor karena memang kerjannya baiik (IT 2)

...dipilih dari yang benar-benar mau kerja, min D3, kalau mereka yang mau kerja sikapnya terhadap pekerjaan juga baik (IT 3)

Sikap positif terhadap pekerjaan terlihat pada orang-orang yang menyenangi pekerjaannya karena akan mendorong rasa nyaman dan kepuasan dalam bekerja, hal ini terlihat pada bidan koordinator dengan "komitmen tinggi" sementara sikap negatif terhadap pekerjaan dapat dilihat dari bidan koordinator dengan "komitmen rendah" karena ingin melepas tanggungjawab yang telah diberikan. Hasil ini didukung dengan penelitian tahun 2014 di Magelang yang menyatakan bahwa terdapat hubungan yang signifikan antara sikap dan motivasi kerja bidan terhadap kinerja bidan dalam pencatatan dan pelaporan. ${ }^{6}$

Sikap kerja memberi keyakinan yang mengandung aspek kognitif, behavior dan kesiapan mental psokologis untuk memberikan reaksi dan bertindak secara positif atau negatif terhadap suatu objek. Sikap ini yang akan memberi penilaian terhadap kinerja bidan sehingga 
sosoknya akan dipertahankan sebagai bidan koordinator di puskesmas oleh pimpinan mereka. Pada Komitmen Afektif dikatakan seseorang karyawan akan memiliki komitmen tinggi bila ingin bertahan dalam pekerjaannya atau dalam organisasi karena menyukai pekerjaannya tersebut. $^{7}$

\section{Komitnen Bidan Koordinator Dari Aspek Dokumen KIA}

Pada penilaian SOP difokuskan pada prosedur ketersediaan dokumendokumen pendukung yang sangat diperlukan dalam pencatatan KIA, dalam buku pedoman PWS KIA dikatakan agar kualitas data baik maka diperlukan catatan wajib diruang KIA seperti Kohort, register dan olah data sederhana dalam bentuk grafik.

Setelah sebelumnya dilakukan obeservasi dan pengisian cek list ruang KIA di puskesmas, ditemukan bahwa bidan koordinator dengan "komitmen rendah" tidak memiliki dokumen KIA yang lengkap untuk mendapatkan informasi lebih lanjut maka ditanyakan alasan mengapa dokumen tidak lengkap.

....sering lupa isi kohort, terlalu banyak kolomnya jadi sedikit bingung, semetara pakai buku kunjungan saja. arsip ada saja, tapi memang kurang lengkap karena sebagian ulun bawa ke rumah (IU1)

....lupa kalau punya kohort dilemari, karena kemarin waktu ganti bikor kada dipadahi jadi kami catat di buku kunjungan harian ai. arsip laporan bisa lupa juga mafoto copy jd langsung kasih ke dinas (IU2)

....tidak sempat mengisi kohort, ulun catat di buku register saja, kebanyakan yang diisi jua. mun arsip itu kemanakah, biasanya ada aja mungkin ada yang pinjam (IU3)

Pernyataan berbeda dapat terlihat pada bidan koordinator dengan "komitmen tinggi”.

....kohort bisa membantu menghitung jumlah kunjungan dan pelayanan yg tepat, seperti kalo anak terlihat jadwal imunisasi. sedangkan arsip laoran sangat penting karena itu bukti kerja bidan (IU4)

....mempermudah mencari data, lebih aman bekerja...jadi kalau sewaktuwaktu diminta siap (IU6)

....dokumen KIA seperti kohort, buku registrasi, peta KIA, kantong persalinan itu penting sekali diisi, dari dokumen itulah data laporan PWS KIA diperoleh dan dianalisa capaiannya..(IT1)

....Kalau isi atau data kohortnya lengkap, membuat laporan PWS KIA sangat mudah dan cepat (IT1)

Dokumen KIA mempunyai peran penting dalam pelaksanaan pencatatan dan pelaporan PWS KIA karena berisikan informasi yang berguna dalam mengambil keputusan terkait progran KIA. Beberapa bidan yang tidak lengkap dokumen KIA terjadi karena tidak terbiasa mencatat pelayanan yang sebenarnya telah dikerjakan. Kondisi ini akan menjadi budaya bila tidak ada kedisiplinan dari diri sendiri, kerjasama rekan sesama program atau pengawasan baik dari kepala puskesmas maupun dari dinas kesehatan.

Pada buku pedoaman PWS KIA disebutkan bahwa Sumber data PWS KIA adalah data-data yang berasal dari 
perkiraan jumlah sasaran (proyeksi), data tersebut dapat diarsipkan atau didokumentasikan pada buku-buku kohort yang tersedia di puskesmas, sehingga apabila bidan koordinator tidak memiliki atau mengisi kohort maka data pada laporan PWS KIA dapat diragukan keakuratannya.

\section{Komitnen Bidan Koordinator Dari Aspek Dukungan Kepala Puskesmas}

Faktor lain yang mempengaruhi kinerja bawahanya adalah dukungan dari atasan. Pimpinan yang baik adalah yang dapat dijadikan panutan, dapat membimbing, mengawasi dan juga mengayomi bawahannya. Pengaruh tidak langsung dari pimpinan puskesmas dapat mempengaruhi bidan koordinator terhadap pelaksanaan pencatatan dan pelaporan PWS KIA.

Dukungan seperti diatas diterima oleh informan "komitmen tinggi" berupa arahan dari pimpinan puskesmas tentang upaya peningkatan pencapaian target puskesmas dan mengingatkan agar laporan jangan sampai terlambat diserahkan ke Dinas Kesehatan Kabupaten Kapuas.

...pimpinana selama ini bagus, mengingat bikin laporan.. Kadang ditanya KIA perlunya apa.. Buku, ballpoint atau apa yang mendukung kerja beliau selalu nanya. (IU2)

....diskusi dengan beliau masalah KIA, laporan jangan terlambat, beliau byk kasih masukan tentang cara pencapaian terget dan kita ada diskusi semua bidan di puskesmas (IU5)

....kami mengharhai semua kerja bidan koordintor, apaun yang diperlukan untuk kalancaran laporan PWS kita sediakan. Kami juga libatkan banyak kegiatan diluar gedung untuk biar bidan koordinator tidak bosan dibalik meja terus. (IT2)

...kami akan selalu mendukung dalam bentuk apapun, termasuk usulan anggaran bila ada inovasi yang muncul dari teman-teman bidan. (IT1)

Beberapa informan mengatakan jika pimpinan Puskesmas mengucapkan kalimat "terima kasih" saja cukup membuat mereka merasa dihargai oleh Pimpinan Puskesmas. Pemimpin adalah sebagai tambahan pengaruh yang melebihi dan mengatasi kepatuhan mekanisme dan pengaruh rutin organisasi dengan kata lain kehadiran pemimpin dapat mempengaruhi dan mendorong atau mengendalikan yang menyebabkan orang lain bertindak atau merespon dan menimbulkan pengaruh positif. $^{8}$

Sedikit mendapat dukungan dari bisa terjadi antara lain karena memang ketidaktertarikan pimpinan terhadap program KIA dan fokus kepada program yang lain. Seharusnya pimpinan memberi dukungan yang sama terhadap semua program puskesmas.

Tujuan memberikan dukungan dari atasan kepada bawahan antara lain meningkatan moral dan kepuasan kerja; meningkatkan produktifitas kerja; meningkatkan kedisiplinan kerja; meningkatkan suasana hubungan dan dukungan kerja yang baik; meningkatkan loyalitas, kreatifitas dan kesejahteraan; mempertinggi rasa tanggung jawab karyawan terhadap tugas-tugasnya.

\section{Komitnen Bidan Koordinator Dari Aspek Dukungan Rekan Kerja}

Kerjasama tim dalam bekerja merupakan salah satu bentuk dukungan dari rekan kerja baik dari sesama program ataupun beda program. Komitmen bekerja 
sama dengan rekan kerja akan sangat membantu meningkatkan kinerja terutama untuk memudahkan memperoleh data-data untuk sinkronisasi antar program sehingga data lengkap dan tidak selisih sebelum laporan PWS KIA diserahkan ke Dinas Kesehatan Kabupaten Kapuas. Beberapa bidan koordiantor dengan "komitmen tinggi: mengatakan selama bekerja sudah terbiasa untuk berbagi informasi data program.

....biasanya saling tukar data dengan program lain seperti gizi dan imunisasi, kalau ada yang tidak singkron.. kami perbaiki (IU4)

....dikungan rekan baik..selama ini mimta data dari program lain lancar..walaupun kadang ada agak susah dimitai data (IU5)

....dukungan teman-teman cukup baik, setiap akhir bulan sering tanya-tanya hasil laporan..kalau beda hasil tapi target sama kita evaluasi, disingkron.. dan diperbaiki (IU6)

\section{Dukungan dari rekan kerja bagi bidan koordinator yang memiliki "komitmen rendah" juga cukup baik walaupun masih ada yang terlihat kerja sendiri tanpa melihat kecocokan data yang target capaiannya sama dengan program KIA.}

....pemegang program lain sering bikin laporan sendiri-sendiri jadi beda data dan kami gunakan data KIA sendiri. Sering nggak singkron sih...tapi kadang kami mau cepat kirim laporan jadi tidak tanya program lain (IU2)

....data biasa kalo perlu baru kita minta, gak setiap bulan. Kita bikin laporan masing-masing saja, karena targetnya juga kadang beda, karena ada yang pakai proyeksi (IU3)

.....rekan kerja KIA dari program lain ya harus mendukung, kami terbiasa duduk bareng untuk menyikrinkan data, jadi...kerjasama timnya cukup baik. (IT2)

....dukungan rekan kerja sangan penting, karena kami di dinkes semua laporan nantinya satu pintu jadi sesama pemegang program saling mendukung berupa berbagi data agar sama data untuk program-program terintegrasi. (IT1)

Dengan adanya bekerjasama dengan rekan kerja mampu memberikan rasa tenang, nyaman dan meningkatkan komitmen kerja karena mampu menyelesaikan masalah bersama sehingga tidak adalagi berbedaan atau selisih data laporan PWS KIA dengan program lain maka ada baiknya antar pemegang program di peskesmas dapat mengikuti langkah Dinas Kesehatan Kabupaten Kapuas melakukan laporan satu pintu agar data-data yang dilaporkan sama.

Mengingat pentingnya dukungan rekan kerja untuk mandapatkan capaian program dengan baik sehingga diharapkan setiap puskesmas dapat meningkatkan dukungan berupa budaya kerjasama tim antar program sehingga data-data dan kegiatan puskesmas manjadi terintergrasi

\section{Komitnen Bidan Koordinator Dari Aspek Suvervisi Dinas Kesehatan}

Dinas kesehatan memiliki kewajiban untuk melaksanakan suvervisi terhadap penanggung jawab program KIA di puskesmas dari kegiatan suvervisi dinas kesehatan dapat manjadi bahan evaluasi 
program KIA termasuk evaluasi pelaksanaan pencatatan dan pelaporan PWS KIA.

Pada penelitian ini diketahui bahwa jadwal suvervisi dari dinas kesehatan Kabupaten Kapuas minimal satu kali dalam setahun, namun juga ada puskesmas yang tidak mendapatkan kunjunan suvervisi untuk program KIA.

....ada kunjungan seperti bimtek dari dinas kesehatan tetapi untuk program KIA, kalau tidak salah tahun kemarin ada 1 kali saja (IU1)

....tahun kemarin tidak ada suvevisi dari program, tapi katanya memang ada yang mau naik tapi nggak bisa masuk karena pas banjir (IU2)

.....sepertinya yang untuk program KIA tahun kemarin tidak ada, yang sekarang belum, kita cuma pernah bertemu di pertemuan program (IU3)

....suvervisi atau monev khusus program KIA tahun kemarin sepertinya belum sampai kesini (IT3)

....memang ada puskesmas yang jauh dengan raport yang jelek karena kerebatasan dana dan waktu belum sempat kita kunjungi..tapi kalau ada seksi lain yg kesana kita titip pesan (IT1)

....dinas masih bisa bertemu saat pertemuan-pertemuan di kabupaten, bila tidak sempat dengan bidan langsung kita titip pesan dengan pimpinan puskesmas atau siapapun yang hadir di pertemuan tersebut. (IU1)

Tetapi pernyataan berbeda dikemukanan oleh bidan koordinator yang mempunyai kategori "komitmen tinggi" dengan jarak lokasi antara puskesmas dan Dinas Kesehatan Kabupaten Kapuas yang terjangkau, kunjungan monev atau kegiatan koordinasi lebih sering dilakukan.

.....mereka sering monev juga ke puskesmas termasuk untuk bidan, kalau ada yang harus dikonfirmasi mereka juga nelpon atau kita yang datang konsultasi ke dinas (IU4)

....dukungan monev dari dinas cukup baik, beberapa kali datang.. saya juga hampir tiap bulan ke dinas tanya-tanya program sekalian menyerahkan laporan PWS KIA secara langsung (IU5)

.....kalau suvervisi dari dinkes ke puskesmas cukup sering (IT2)

.....bimtek kami jadwalkan minimal $1 \mathrm{x}$ setahun ada juga yang lebih sering, seperti ke puskesmas-puskesmas yang terjangkau, paling tidak hanya1 hari perjalananlah, koordinasi juga bisa lewat telpon (IT1)

Tujuan dilaksanakan kegiatan supervisi oleh dinas kesehatan antara lain untuk mengetahui hal-hal apa yang menjadi masalah dalam pelaksanaan pencatatan dan pelaporan PWS KIA serta membantu memecahkan masalah masalah tersebut. Dari pernyataanpernyataan bidan koordinator dan telaah hasil observasi dokumen terlihat bila puskesmas yang sering di suvevisi oleh dinas memiliki kerja dengan "komitmen yang tinggi”. Penelitian sebelumnya juga menyatakan bahwa supervisi rutin dari Dinas Kesehatan dibutuhkan untuk monitoring dan evaluasi pencatatan dan pelaporan oleh bidan. ${ }^{9,10}$

Kegiatan suvervisi ke puskesmas sangat diharapkan memiliki frekuensi yang lebih sering dan dengan durasi kunjungan yang cukup lama dan 
memberitahu materi KIA sampai pelaksana di lapangan benar-benar mengerti tentang pencatatan dan pelaporan PWS KIA juga sebagai bentuk dukungan dinas kesehatan terhadap program yang merata.

...kunjungan suvervisi sangat
membantu, kalau bisa orang dinas
bermalam dikampung sini mengajari
PWS sampai kami benar-benar bisa
(IU1)

....bila ada bimtek dari dinas tapi sebentar sekali, arahan yang diberikan kurang jelas, cuma kasih tahu yang salah (IU2)

.....kami mengakui memiliki keterbatasan waktu untuk suvervisi, khusus puskesmas terjauh, untuk PP kesana bisa memakan waktu 4 hari. Karena kita juga banyak kerjaan dan fokus ke program lain dulu (IT1)

....Biasanya untuk ke puskesmas yang jauh kita berangkat bersama-sama dengan program lain, sampai dilokasi juga berbagi waktu untuk pengarahan ke masing-masing penanggung jawab program (IT)

Mengingat pentingnya kegiatan supervisi program dari Dinas untuk mandapatkan capaian program dengan lebuh baik sehingga diharapkan kegiatan supervisi program KIA diperbanyak dengan mempertimbangkan waktu dan kualitas kunjungan seperti memberi atau menyampaikan materi sesuai permasalahan yang ada.

\section{KESIMPULAN}

Bidan kordinator yang lebih berkomitmen dalam pencatatan dan pelaporan PWS KIA antara lain bidan koordinator yang memiliki pengalaman kerja yang lama, memiliki keinginan bertahan dengan jabatan kerjanya, memiliki dokumen lengkap, mendapat dukungan yang baik dari pimpinan, mendapat dukungan yang baik dari rekan kerja serta mendapat kesempatan lebih sering mendapatkan supervisi.

\section{UCAPAN TERIMA KASIH}

Penulis mengucapkan banyak terimakasih Dinas Kesehatan Kabupaten Kapuas dan seluruh Bidan Koordinator Puskesmas di wilayah kerja Kabupaten Kapuas yang telah berpartisipasi dalam proses penelitian ini.

\section{DAFTAR PUSTAKA}

1. Departemen Kesehatan RI. Pedoman PWS KIA. Depkes RI. Jakarta. 2009

2. Peraturan Menteri Kesehatan Republik Indonesia Nomor 1464/Menkes/ Tentang Standart Profesi Bidan. 2010

3. Departemen Kesehatan RI. Pedoman Bidan Koordinator. Depkes RI. Jakarta. 2010.

4. Dharmawan Y, Wigati PA, Dwijayanti F. Kinerja petugas dalam pencatatan dan pelaporan PWS KIA di Puskesmas Duren. KEMAS: Jurnal Kesehatan Masyarakat. 2015 Jan 19;10(2):210-7.

5. Meyer, J.P. \& Allen, N.J. Commitment in the workplace: Theory, Research, and Application. Thousand Oaks, CA: Sage Publication, Inc. 1997

6. Kusyanti F. Faktor Motivasi Dan Sikap Yang Berhubungan Dengan Kinerja Bidan Dalam Pemantauan Pencatatan Pelaporan Posyandu Di Wilayah Kerja Dinas Kesehatan Kabupaten Magelang Tahun 2014. Medika Respati: Jurnal Ilmiah Kesehatan. 2017 Jul 12;12(3):31-6.

7. Hasibuan MSP. Manajemen Sumber Daya Manusia. Ed Revisi. Jakarta Bumi Aksara. Epub ahead of print 2011. DOI: 10.1017/CBO9781107415324.004. 
8. Widyatmini W, Hakim L. Hubungan kepemimpinan, kompensasi dan kompetensi terhadap kinerja pegawai dinas kesehatan kota depok. J Ilm Ekon Bisnis; 13.

9. Fitriyani F, Zuhana N, Prafitri LD. Studi Deskriptif Pencatatan Dan Pemanfaatan Kartu Ibu Oleh Bidan. Jurnal Ilmiah Bidan. 2018 Dec 28;3(3):35-42. 